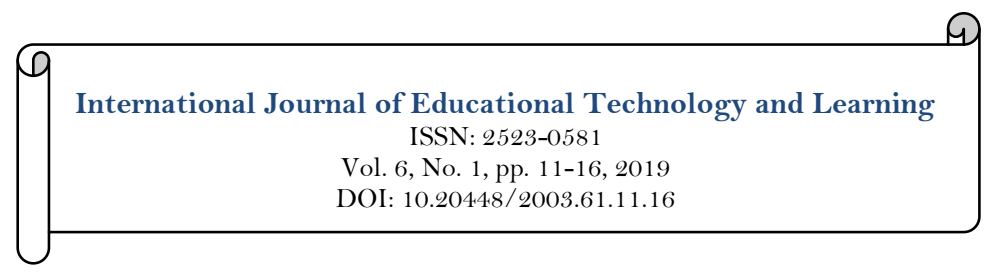

check for
updates

\title{
Ensuring Content Representativeness: Perceptions of Senior High School Teachers in Ghana
}

\author{
Daniel Asamoah ${ }^{1 *}$ \\ Benjamin Sundeme ${ }^{2}$ \\ Aaron Adusei ${ }^{3}$ \\ Moses K. K. Ocansey ${ }^{4}$ \\ William Ntiamoah Ntim ${ }^{5}$ \\ $1,2,3,4,5$ Department of Education and Psychology University of Cape Coast, Ghana. \\ 'Email:daniel.asamoah1@stu.ucc.edu.gh
}

\begin{tabular}{|c|c|}
\hline tract & \\
\hline $\begin{array}{l}\text { For a meaningful classroom assessment to be feasible, teachers must ensure } \\
\text { adequate content representativeness when crafting their items. The study } \\
\text { sought to find out the perceptions of senior high school teachers on how well } \\
\text { they ensure content representativeness in their classroom assessment } \\
\text { procedures in Ghana. Underpinned by the theory of validity, the study used } \\
\text { the qualitative research approach. The purposive sampling procedure was } \\
\text { used to select a sample of } 25 \text { participants for the study. The interview guide } \\
\text { was used to collect data for the study. The data was analysed manually } \\
\text { using the thematic approach. The results of the study revealed that senior } \\
\text { high school teachers least ensure content representativeness in their } \\
\text { assessment procedures because they fail to develop and use a table of the test } \\
\text { specification. In furtherance to this, the study showed that senior high school } \\
\text { teachers do not consult measurement experts or curriculum planners to } \\
\text { thoroughly judge the items the teachers craft in ensuring content } \\
\text { representativeness. It is recommended among others that there should be the } \\
\text { need for educating teachers on what table of a test specification is, and how } \\
\text { to develop and use it. }\end{array}$ & $\begin{array}{l}\text { Licensed: } \\
\text { This work is licensed under a } \\
\text { Creative Commons Attribution } 4.0 \\
\text { License. } \\
\text { Publisher: } \\
\text { Scientific Publishing Institute }\end{array}$ \\
\hline
\end{tabular}

Funding: This study received no specific financial support. The study was funded by the researchers. Competing Interests: The authors declare that they have no competing interests.

Acknowledgement: All authors contributed equally to the conception and design of the study.

\section{Introduction}

Educational measurement and assessment have become integral components of teaching and learning. As part of assessment and measurement, classroom teachers need to develop reliable and valid test items that will help them to know the extent to which their students have successfully mastered the concepts that have been taught (Agostino, Karpinski, \& Welsh, 2011; Amedahe \& Asamoah-Gyimah, 2018).

When valid and reliable assessment procedures are used, decisions on students' placement, selection and certification, among others, become feasible.

With a critical look at the relevance of classroom assessment, there is the need to ensure that items in the test are well crafted, valid and reliable. This is because major educational decisions on students are made from the outcome of the test. It is in this regard that Crocker and Algina (2008) stress that test constructors, assessors and users must make efforts to improve the validity and reliability of the test items. Invariably, the more reliable and valid the items on the testing instrument, the better the approximation on the true characteristics possessed by test takers is made (Quansah, Amoako, \& Ankomah, 2018). 
It should be pointed out that classroom teachers construct a series of test to measure and assess students' learning outcomes. While teachers construct their tests, Nitko (2004) echoes that they must have adequate test construction skills and comply with test construction principles in order to improve on the validity and reliability of the test results.

However, it has been empirically established by Quansah et al. (2018), Onyechere (2000) and Quansah and Amoako (2018) that teachers have difficulties in constructing reliable and valid test items to measure and assess students' learning outcomes. For instance, by using document analysis, Quansah et al. (2018) found from an end-of-term integrated science, core mathematics and social studies examination questions that senior high school teachers have limited skills in test construction.

Specifically, it was found that teachers had difficulties in content representativeness and the relevance of the test. The difficulties teachers face on content representation raise questions on the content validity of the tests they might have used. Similarly, Quansah and Amoako (2018) reported that teachers have negative attitudes on item writing, item reviewing and assembling of the items. The implication of this is that teachers are likely to make inaccurate decisions on students' learning outcomes which can consequently affect their educational development.

In the works of Onyechere (2000) teachers' test construction skills are poor. This is because, teachers acknowledged that they refer to already existing items to assess students' learning outcomes even without modifying the items (Onyechere, 2000). This goes against the principles of test construction because, items are not supposed to be lifted from textbooks nor other existing materials, as such practices affect content representativeness (Ramsey \& Hewitt, 2005).

In Ghana, the Curriculum Research and Development Division (CRDD, 1999) found that teachers at the basic school level have inadequate skills and competencies in testing. With reference to the finding of CRDD (1999) Estey (as cited in Quansah et al., 2018) had cautioned that the Ghana Education Service ought to make an assessment and its related courses compulsory across the various colleges of education in Ghana. This is important because teachers who graduate from the colleges of education will be exposed to the skills in test construction and comply with its principles.

The difficulties teachers face in constructing valid and reliable test items have attracted researchers' attention from the global perspective especially in the field of educational measurement and assessment (CRDD, 1999; Hamafyelto, Hamman-Tukue, \& Hamafyelto, 2015; Quansah et al., 2018). These attempts were made to uncover the exact difficulties of classroom teachers regarding their test construction skills. According to the aforementioned authors, test constructors and classroom teachers face difficulties, among them, are; ensuring content representativeness, practicality, fairness, reliability, efficiency and objectivity. For the purpose of this study, the emphasis is laid on content representativeness. As mentioned earlier, all the studies used self-reported instruments in describing teachers' test construction skills and competencies in the areas identified.

The studies used questionnaires (CRDD, 1999; Crocker, 1997; Hamafyelto et al., 2015; Kazuko, 2010) and document analysis (Quansah et al., 2018) to gather information on teachers' test construction skills and made generalizations thereof. In particular, these studies failed to probe the participants further on their perceptions on test construction and especially their perceptions on content representativeness, and this by far gave such studies a limited focus. This is critical because, by asking teachers to give written responses to questions and by observing sample test documents, respondents are likely to create and give positive impressions about themselves on their test construction skills or replicate items on a standardised high stake testing instruments to measure students' learning outcomes.

In addition, the aforementioned studies failed to consider in-depth perceptions of classroom teachers on content representativeness which is critical in ensuring content validity and writing of better items for assessment purposes. A critical analysis of the literature suggests that the use of quantitative approach and qualitative document analysis methodologies failed to tease out the views and perceptions from the stand point of the classroom teachers who ensure content validity and representativeness. It is against this backdrop that this study seeks to examine the content representativeness of classroom teachers from the angle of qualitative research approach. This is to provide an in-depth analysis to issues regarding how well classroom teachers ensure content representativeness in their classroom assessment procedures.

\section{The Theory of Validity, Content Representativeness and Content Validity}

The study was underpinned by the theory of validity. According to Nitko (2004) validity is the degree to which evidence and theories support the interpretations of test scores regarding the proposed uses of tests. Validity from the view of Crocker (1997) is the soundness or appropriateness of the interpretations and uses of students' assessment results. Validity emphasises the assessment results which we interpret, and not the instrument or procedure itself. The process of validation involves accumulating evidence to provide a sound scientific basis for the proposed score interpretations and uses (Hsieh, 2013). 
It has to do with the meaning of the scores and the way one uses the scores to make decisions rather than with the test being used to produce the scores. Validity is a unitary concept which focuses on content validity, construct validity and criterion validity. For the purpose of the study, content validity is emphasised.

The content validity evidence refers to the content representativeness and relevance of tasks or items on an instrument (Nitko, 2004). Judgments of content representativeness focus on whether the assessment tasks are a representative sample from a larger domain of performance.

One way to ascertain content-related validity of a test is to develop and use the table of specification when developing test items. The table of specification is a two-way chart showing the content coverage and the instructional objectives to be measured, by an expert (Nitko, 2004). Crocker and Algina (2008) note that, when the test specification table is developed and used, it ensures the representativeness of items across the topics covered, and the corresponding learning outcomes. One way to ensure content validity is to clearly specify the entire domain of instructionally relevant tasks that will be used to measure students' learning outcomes (Hamafyelto et al., 2015; Kazuko, 2010).

Content validity can also be determined by a thorough inspection of items on a test, usually by curriculum and measurement experts (Crocker \& Algina, 2008; Nitko, 2004). This is carefully done to judge the items on whether or not they represent the total domain of the area of interest of the test. Content validity and representativeness are quintessential for ensuring validity.

A teacher's ability to craft items to represent the entire area or content of assessment needs expert training or skill. It is in this regard that in Ghana, every trained or professional teacher has studied a course in measurement and evaluation such as assessment, to better understand these critical issues in their classroom assessment of students. The ultimate question however is, how well do teachers know, use and develop test specification table or get their items inspected to ensure that they set questions that sample the entire domain of interest? Although studies have used the quantitative and document analysis procedures to partially address content representativeness, validity and teachers' test construction skills as a whole, there is the need to use qualitative approach to uncover senior high school teachers' perceptions on content representativeness. This will give a broader view on how well teachers ensure content representativeness and validity in general when assessing their students' progress.

\section{Methodology}

The study used the qualitative research design approach. Specifically, the case-study method was used because there was the need to gather in-depth understanding of how senior high school teachers ensure content representativeness. The study area was the Kumasi Metropolis which can be found in the Ashanti Region of Ghana. This is of the view that, the senior high schools in the metropolis mirrors Ghana's educational system and that what happens within the metropolis in terms of education is the true reflection of educational situations in Ghana. The participants comprised senior high school teachers which included heads of departments. Through purposive sampling procedures, twenty-five (25) senior high school teachers out of which ten (10) were heads of department, were selected for the study. Purposive sampling was used because the participants possessed certain characteristics of interest to the study and for with them, the right information could be sourced and have gained enough experience to inform the study. The inclusion criteria for the study were senior high school teachers who have taught for ten years or more. The reason for the inclusion criteria was to solicit in-depth perceptions on the study variables from participants who had enough teaching experience. The sample size of twenty-five (25) participants was used because, Bryman (2012) shares the view that the sample size could be adjusted in the course of data collection bearing in mind the concept of saturation and adequacy in qualitative data collection. In mindful of this, twenty-five (25) participants were sampled when the level of saturation and adequacy were reached. According to Myers (2000), small sample size is often accurate to offer an in-depth and useful data in conducting qualitative research. Based on the position of Myers (2000) from an accessible population of 310 senior high school teachers, twenty-five (25) participants were deemed appropriate for the study.

Interview guide on content representativeness was used to collect data for the study. The interview guide covered six (6) questions on content representativeness. On a one-on-one basis, participants were asked the six questions and follow-up questions were asked based on the answers that were given. Specifically, interviews were held in participants' places of convenience. In the process to ensure validity and reliability of the interview guide, the items were given to experts in measurement and evaluation to assess each item in the context of clarity, ambiguity, relevance and generality. Moreover, Cohen, Manion, and Morrison (2011) argues that the establishment of validity and reliability of a qualitative research is about the trustworthiness (credibility) of the data. Qualitative research is credible, when it accurately represents the experience of the study participants and participants' validation. The following were observed to ascertain the trustworthiness of the research. First, all the participants were taken through the same main themes. Second, the researcher interviewed the participants to the point of data saturation (no new information was raised). Before the conduct of the interview, ethical issues such as confidentiality, anonymity, privacy, right of participation and voluntary participation were all considered. The collected data was organised and analysed manually using the thematic approach. The approach involved shifting and sorting of data in line with issues and themes, and 
transcribing the interviews into various themes based on the research questions. In the analysis, other responses were reported verbatim to explain the general observations on the gathered data. Number coding was used by assigning numbers such as one, two and three to the themes respectively.

\section{Findings and Discussion}

The purpose of the study was to find out how rigorous senior high school teachers ensure content validity in their classroom assessment procedures. In order to achieve this, senior high school teachers were asked issues that pertain to the development and use of the table of test specification and their ability to consult experts to judge the items they write to reflect the entire domain of the universe teachers assess their students. After the analysis, it was revealed that senior high school teachers least ensure content representativeness in their assessment procedures. The participants reported that, despite their teaching experiences, they did not develop and use table of test specification. The participants indicated that, although they did not have the expertise, they used their teaching experience to judge how the items they wrote sampled the entire area or content of the assessment. To confirm these findings, a participant opined on the development and use of test specification table as follows:

I have heard of test specification table but I don't use it. I don't even know how to develop it. I was exposed to it when I was in the training college. Since then I have just forgotten about it. I don't remember how to develop it. (A participant aged 43: November 9, 2018).

Another participant who was a head of department alluded to the development and use of table of test specification as follows:

I am aware of test specification table but I don't use it. After all, I have taught for a period of time and I know the kind of questions to set for my students. Frankly, no teacher uses it. (A participant aged 45: December 11, 2018).

Another participant had this to say on development and use of table of test specification:

Looking at the current trends of questions, it is okay to give students some likely past questions. This will help them to know the kind of questions that usually come in their final examinations. I don't think I know how to develop or use table of test specification. Most at times, I look at the objectives of my lessons and set questions. (A participant aged 37: November, 23, 2018).

It can be inferred from the views of the participants that, they had heard of table of test specification but none of them knew how to develop or use it. The responses confirm that the participants failed to use the table of test specification in the assessment instruments they have been using. Amedahe and Asamoah-Gyimah (2018) stipulate that when the test specification table is developed and used, it ensures the representativeness of items across topics covered, and the corresponding learning outcomes. The table of test specification is relevant and critical because it ensures the content validity evidence as part of the theory of validity. From the theory of validity, content-related evidence or validity of a test is particularly achieved when the table of test specification is developed and used (Nitko, 2004). In other to validate the views of the participants form a wider context, another participant who was a head of department commented that:

No teacher in my department uses table of test specification. I feel that they have all forgotten about it. There is no law to force teachers to use the table of test specification in writing their questions. No law regulates how teachers should set their questions. As head of department, I always see teachers repeating past questions any time they are to submit question for exams. (A participant aged 51: December 12, 2018).

The implication of the findings is that, the content validity of the test items on the assessment instruments the participants might have used would be missing. By implication, inability of the participants to develop and use the test specification table might have allowed them to sample or use irrelevant items that might not be contained in the domain of interest.

Therefore, when decisions are made using the results of the assessment instruments the participants might have used, the validity regarding the use and interpretation of the assessment results would be missing which consequently violates the theory of content validity. This is because, there is a greater likelihood that the participants might have used items that might not be a representative of the entire domain of interest as far as the learning objectives were concerned.

Hamafyelto et al. (2015) and Amedahe and Asamoah-Gyimah (2018) point out that, one of the ways to ensure content validity is to specify the entire domain of instructional tasks that are relevant in measuring students' learning outcomes. To support the positions of Hamafyelto et al. (2015) and Amedahe and AsamoahGyimah (2018) Nitko (2004) opines that content validity is highly achieved when the table of test specification is used. Therefore participants' inability to develop and use the table of test specification means that the content representativeness of their assessment instruments might have been low or even non-existing.

Crocker and Algina (2008) stress that content representativeness can be checked by thorough inspection of items on a test, usually by curriculum and/or measurement experts. In this regard, senior high school teachers were queried on whether they were able to ensure such inspections. Specifically, a participant commented as follows: 
I do not send questions to curriculum or measurement experts to check whether the questions represent the entire area of coverage. Most at times, my experiences and observations help me to determine that. I don't need the services of such experts to judge my questions in that respect. (A participant aged 48: October 8, 2018).

Another participant had this to say on whether curriculum or measurement experts judge their items to ensure content representativeness:

Frankly, no senior high school teacher does that. In my case, I set questions based on what I teach and sometimes refer to past questions on what I have taught since most of them are standardised questions from the West African Examination Council. (A participant aged 51: October 16, 2018).

The revelations by the participants have crucial implications. According to Amedahe and AsamoahGyimah (2018) the practice of lifting items from textbooks or other existing materials affect content representativeness and test construction in general. This is evident because, the lifted questions might not measure the same behavioural objective of interest to the assessor. It can be inferred from the responses of participants that they fell on their experiences to write or set items for assessment, and that, they did not find it necessary to consult measurement or curriculum developers or planners. To confirm these findings, a participant who was a head of department had this to say:

For my department, teachers set their questions and submit to me especially when the questions are end of terms examination questions. As head of department, I go through the questions and forward them to the examination board for printing. (A participant aged 45: November 5, 2018).

Another head of department from a different department shared in the same view as follows:

Teachers assess their students in their own way. No expert check the questions they set, whether classroom exercises or examination questions. (A participant aged 51: November, 10, 2018).

The responses of the participants confirm that they do not consult any expert for inspection of their items to ensure content representativeness. These actions of the participants are more likely to introduce errors which will consequently affect the content representativeness and the overall content validity of the assessment instruments they might have used (Crocker \& Algina, 2008). Specifically, it cannot be denied that the assessment instruments the participants might have used ensured to a level, a bit of content representatives, the fact that they failed to use table of test specification and failed to employ the services of key experts suggest that, they least ensured content representativeness. This might have affected the content validity of their assessment instruments because, from the theory of validity, judgments of content representativeness is focused on whether the assessment tasks are a representative sample from a larger domain of performance.

\section{Conclusions and Recommendations}

With reference to the purpose and the findings of the study, it is concluded that the senior high school teachers do not make efforts to ensure optimum content representativeness.

This is evident because senior high school teachers reported that they failed to develop and use a table of test specification which is important to ensure content representativeness and content validity in general. In addition, senior high school teachers fail to consult measurement experts and/or curriculum planners and developers in their fields.

The reason could be that these experts are unavailable and that senior high school teachers hardly see the professionals or fail to see them at all. It is therefore recommended that stakeholders in education and measurement experts must educate teachers at all levels of education in Ghana on the need to develop and use the table of test specification in crafting their items for students' assessments. The study further recommends the need for the organisation of in-serving training and seminars by assessment experts on test construction and specifically the meaning of table of test specification, how to develop it, and how it is used. Lastly, it is recommended that teachers should cultivate the habit of using the test specification table and see measurement experts and/or curriculum experts where necessary, on item writing.

\section{References}

Agostino, J., Karpinski, A., \& Welsh, M. (2011). A method to examine content domain structures. International Journal of Testing, $11(4), 285-307$.

Amedahe, F. K., \& Asamoah-Gyimah, K. (2018). Introduction to measurement and evaluation. Cape Coast: University of Cape Coast Press.

Bryman, A. (2012). Social research methods (4th ed.). New York: Oxford University Press

Cohen, I., Manion, I., \& Morrison, K. (2011). Research methods in education (7th ed.). London: Routledge.

CRDD. (1999). Investigation into student assessment procedures in public junior secondary schools in Ghana. Accra: Ghana Education Service.

Crocker, L. (1997). Assessing content representativeness of performance assessment exercises. Applied Measurement in Education, $10(1)$, 83-95.

Crocker, L., \& Algina, J. (2008). Introduction to classical and modern test theory. Ohio: Cengage Learning Press.

Hamafyelto, R. S., Hamman-Tukue, A., \& Hamafyelto, S. S. (2015). Assessment teacher competence in test construction and content validity for teacher made examination questions in commerce in Borno State, Nigeria. Journal of Education, 5(5), 123-128. 
Hsieh, C. N. (2013). Establishing domain representations for a large-scale language assessment for young EFL learners. Midwest Association of Language Testers, Michigan State University, East Lansing, MI.

Kazuko, J. W. (2010). Japanese high school mathematics teachers' competence in real world problem solving. Keto Academy of New York and Teachers College, Columbia University.

Myers, M. D. (2000). Qualitative research in information systems. MIS Quarterly, 12(2), 241-242.

Nitko, J. A. (2004). Educational assessment of students. New Jersey: Prentice Hall.

Onyechere, I. (2000). New face of examination malpractices among Nigerian youths. The guardian Newspaper July 16.

Quansah, F., \& Amoako, I. (2018). Attitude of senior high school teachers towards test construction: Developing and validating a standardised instrument. Research on Humanities and Social Sciences, 8(1), 25-30.

Quansah, F., Amoako, I., \& Ankomah, F. (2018). Teachers' test construction skills in senior high schools in Ghana: Document analysis. International Journal of Assessment Tools in Education, 6(1), 1-8.

Ramsey, C., \& Hewitt, D. (2005). A methodology for assessing sample representativeness. Environmental Forensics, 6(1), 71 75 . 